\title{
US to monitor arrivals from Liberia, Sierra Leone, and Guinea
}

\author{
Michael McCarthy
}

Seattle

US health officials will begin to actively monitor all travelers arriving from the three west African countries affected by the Ebola epidemic, Liberia, Sierra Leone, and Guinea, the US Centers for Disease Control and Prevention announced 22 October.

The monitoring will begin 27 October in six states that are the destinations of $70 \%$ of travelers from these countries, New York, Pennsylvania, Maryland, Virginia, New Jersey, and Georgia, said the CDC's director, Tom Frieden, at a press briefing.

Most travelers from the affected countries are either US citizens or long time legal residents, Frieden said. "This includes journalists and people helping in the response, including our staff here at CDC."

Air travelers from the affected countries must now enter the US through five designated airports where they are questioned about possible exposure to the Ebola virus and symptoms and have their temperatures checked. Travelers who have a high temperature or worrying symptoms or who are thought to be at high risk of infection are passed to CDC officials on site for further evaluation. Those at low risk are asked to monitor themselves and to report to authorities if they develop fever or symptoms.

Ebola virus disease is spread by direct contact with bodily fluids from a person who has symptoms of infection. People who have not yet developed symptoms are not infectious even though they themselves are infected.

Under the new protocol, all travelers arriving from the affected countries will be contacted by state or local health officials daily for 21 days after their last possible date of exposure to the virus. The incubation period for developing Ebola virus disease is two to 21 days, and most people develop symptoms eight to 10 days after infection.

During the monitoring period, travelers will be required to take their temperature twice a day, morning and night, and to contact health officials daily to report their temperatures and whether they have developed any symptoms seen with the disease, such as headache, joint and muscle aches, weakness, diarrhea, vomiting, stomach pain, lack of appetite, or abnormal bleeding. If they plan to travel while they are in the country, the travelers will have to make arrangements so that their monitoring can continue during their trip, Frieden said. "If a traveler doesn't report in, the state or local official will take immediate steps to find the person and ensure that active monitoring continues on a daily basis."

To help the travelers monitor their condition, each will, on arrival in the US, receive a Check and Report Ebola (CARE) kit, which will include a tracking log, a pictorial description of symptoms, a thermometer, and a wallet card with information on whom to contact if they develop symptoms and that they can present to a healthcare provider.

Should a traveler develop symptoms, health officials will move to isolate the traveler and transport him or her safely to a local hospital where staff have been trained to receive patients with potential Ebola virus disease.

Frieden said that travelers who do not go to the six states initially being targeted for the new monitoring program tend to head to a wide variety of locations across the country so that individual states end up seeing only a "handful" of travelers. The CDC will be working to establish monitoring systems with local health authorities in those states, he said.

The new monitoring program will add another level of protection to reduce the risk of an outbreak of Ebola virus disease in the US, Frieden said, but he added, "We can't get to zero risk until we stop the outbreak in Sierra Leone, Liberia, and Guinea."

Cite this as: BMJ 2014;349:96433

๑ BMJ Publishing Group Ltd 2014 